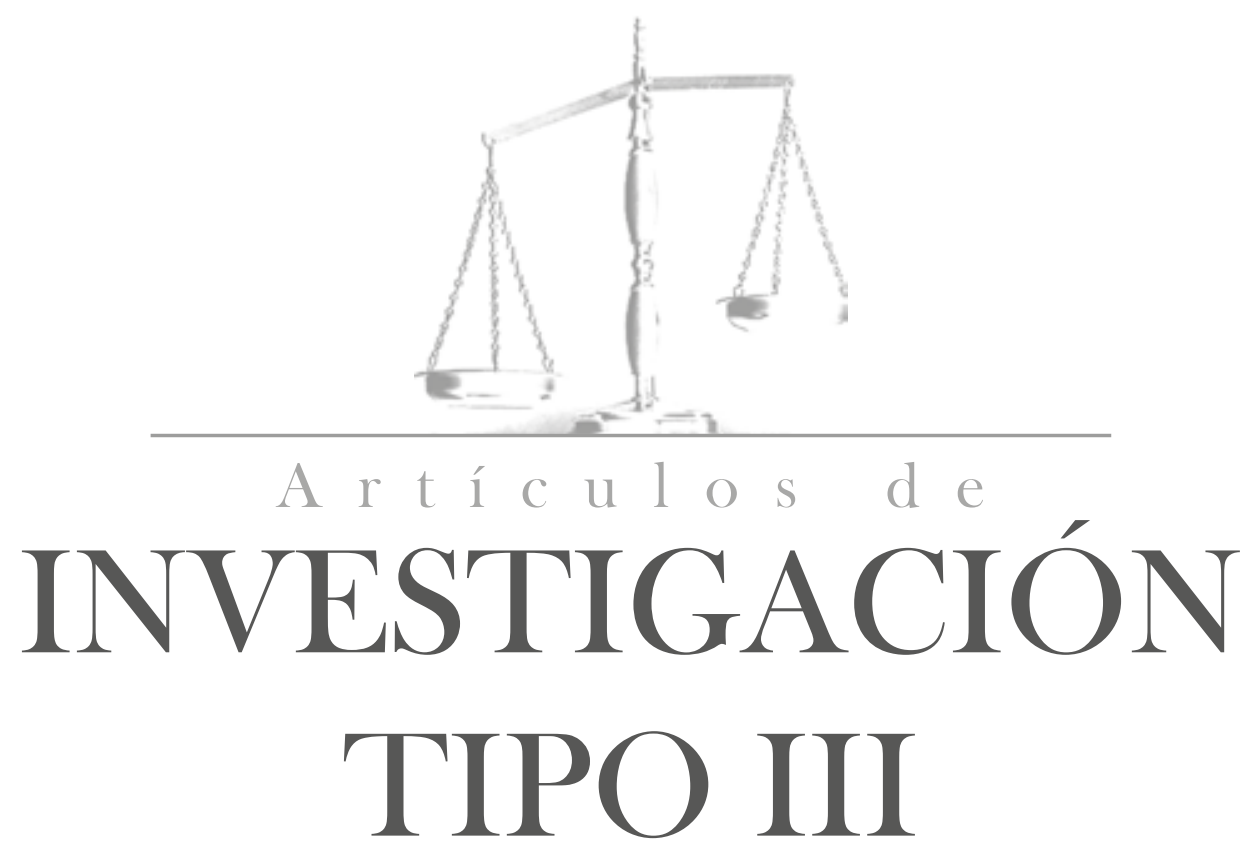




\section{Luis Fernando Trejos Rosero** $\mid$ Aproximación a las dinámicas del crimen organizado en la ciudad de Barranquilla. El caso del Frente José Pablo Díaz de las Autodefensas Unidas de Colombia (2000-2006)* Approximation to the dynamics of the crime organized in Barranquilla's city. The case of the Frente Jose Pablo Diaz de las Autodefensas Unidas de Colombia (2000-2006)}

Recibido: 15 de octubre de 2013 / Aceptado: 21 de noviembre de 2013

Palabras clave:

Paramilitarismo, Crimen organizado, Control social, Narcotráfico, Violencia.

Key words:

Paramilitarismo, Organized crime, Social control, Drug trafficking, Violence.

\section{Resumen}

El presente artículo de revisión se propone realizar una aproximación a las dinámicas operativas y al proyecto de orden social instaurados por el Frente José Pablo Díaz de las Autodefensas Unidas de Colombia en Barranquilla. También se busca demostrar que la presencia del paramilitarismo en esta ciudad, no obedeció a una estrategia contrainsurgente sino a sus estrechos vínculos con el narcotráfico y el crimen organizado y que en términos políticos logró de manera parcial la reconfiguración cooptada del Estado durante el periodo comprendido entre 2000 y 2006.

\footnotetext{
Abstract

The present article of review there proposes to realize an approximation to the operative dynamics and to the project of social order restored by the Frente Jose Pablo Diaz de las Autodefensas de Colombia in Barranquilla. Also one seeks to demonstrate that the presence of the paramilitarismo in this city, counter insurgent did not obey a strategy but his narrow links with the drug trafficking and the organized crime and that in political terms it achieved in a partial way the reconfiguration coopted of the State during the period understood between 2000 and 2006.
}

* Este artículo, es fruto de la investigación: "Violencia paramilitar y cooptación política en el Caribe colombiano", adelantada por el autor en el marco del Grupo de Trabajo CLACSO "Movimientos sociales y movimientos revolucionarios en América Latina y el Caribe", desarrollada actualmente dentro del Grupo de Investigación Agenda Internacional de la Universidad del Norte. Una versión corta de este trabajo, fue publicada en la Revista Economía del Caribe.

** Doctor en Estudios Americanos con mención en Estudios Internacionales (IDEA/USACH). Profesor e investigador del Departamento de Historia y Ciencias Sociales de la Universidad del Norte, Barranquilla (Colombia). Investigador Asociado del Instituto de Altos Estudios de América Latina y el Caribe, Universidad del Norte. Miembro del Grupo de Investigación Agenda Internacional de la Universidad del Norte. trejos1@uninorte.edu.co; luifer385@gmail.com 
Contexto teórico de la participación paramilitar en el conflicto armado colombiano

En este trabajo se utilizan las teorías que explican las guerras civiles post-guerra fría desde variables económicas, esto debido a que si bien el fenómeno paramilitar tiene sus orígenes en la década de los 60 del siglo pasado ${ }^{1}$, solo es hasta 1998 con la fundación de las Autodefensas Unidas de Colombia (AUC), cuando alcanzan sus mayores desarrollos económicos, políticos y militares y su mayor expansión territorial ${ }^{2}$.

Dentro de los análisis realizados sobre los conflictos armados ocurridos a partir del final de la guerra fría, hay una línea de investigación que ha planteado el debate sobre las variables sociales, políticas y económicas presentes en las acciones armadas. Esta corriente teórica, conocida como "economía del conflicto", dirige sus argumentos en contra de las teorías que consideran que factores como la pobreza, la injusticia y la desigualdad social de las clases menos favorecidas son determinantes en el nacimiento, desarrollo y legitimación político-militar de la insurgencia. Para los investigadores de las economías de los conflictos armados, la clave de la organización y permanencia temporal de los ac-

1. Según Botero (1996), los primeros grupos paramilitares nacieron en Colombia autorizados por la Ley 48 de 1964. Esta ley permitió la creación de grupos de autodefensa, los que posteriormente fueron organizados por medio de la orden interna del Ejército Nacional número 005 de 1969, expedida por el Alto Mando de las Fuerzas Armadas y por medio de otras disposiciones contraguerrilleras como la EJC 3-10.

2. Para un análisis teórico del fenómeno paramilitar, véase: Kalyvas, Stathys y Arjona, Ana (2008). "Paramilitarismo: una perspectiva teórica", en: Rangel, Alfredo (editor), El poder paramilitar. Bogotá: Fundación Seguridad \& Democracia, Editorial Planeta. tores armados ilegales radica en su capacidad de acceso a recursos económicos (Camacho, 2002).

Desde esta óptica, la motivación de los conflictos armados es irrelevante, ya que lo único importante es la capacidad de financiamiento de la organización armada. De este modo, sin desconocer las causas sociales y políticas que originan los conflictos, lo determinante para el sostenimiento temporal de las acciones armadas radica en la capacidad de los ilegales para acceder a recursos económicos (Collier, 2001).

Paul Collier (2001), al analizar las tendencias presentes en una serie de guerras observadas durante el periodo 1965-1999, plantea dos conclusiones: la primera, que las causas de emergencia de conflictos armados se relacionan directamente con unas cuantas condiciones económicas, tales como la alta dependencia de exportaciones de materias primas y rentas nacionales escasas; la segunda, que fracturas étnicas y territoriales, el descontento social, la ausencia de democracia y la desigualdad social (causas objetivas), no han producido efectos sustanciales sobre las causas de emergencia de los conflictos. En su hipótesis central sostiene que "esto se debe a que las guerras civiles se producen donde hay organizaciones armadas financieramente viables".

Dentro de esta línea de investigación, Mary Kaldor (2001), Michael Hart y Antonio Negri (2004) establecen un marco analítico para el estudio de lo que ellos denominan una nueva forma de violencia organizada, que aparece en la década de los 80, especialmente en Europa del Este y África. Estas "nuevas guerras globales 
permanentes" o "guerras degenerativas" se desarrollan en contextos de debilidad estatal, entre otras cosas por la pérdida del monopolio legítimo de la violencia. Esta situación se presenta por la integración militar global, por la privatización de la violencia relacionada con el crimen transnacional y el paramilitarismo, y por la creciente disminución de la legitimidad política del Estado en contextos de corrupción institucional, crisis fiscales y económicas.

Para estos autores, las "nuevas guerras" presentan cuatro características distintivas. La primera se refiere a la renuncia a los tradicionales marcos nacionales e internacionales como medio obligado para establecer su delimitación espacial, ya que, al determinar su "localidad", deben incluirse sus cientos de repercusiones transnacionales, lo que dificulta la clásica distinción entre conflictos internos y externos. La segunda, que se desprende de la primera, es la contextualización de las "nuevas guerras" dentro de la globalización, entendiendo esta como el aumento sostenido de las interconexiones políticas, económicas, culturales y militares a escala global. La tercera es que, al dificultarse la centralización de las acciones armadas, los combatientes buscan la captura de territorios y el control político de la población por medio del terror. La cuarta característica de estas guerras es que son racionalistas, en el sentido de que los actores armados aplican el pensamiento racional a sus objetivos políticos, por lo cual no tienen en consideración restricciones de tipo normativo. De ahí que acciones militares rechazadas ampliamente por la comunidad internacional, tales como la destrucción de infraestructura y los ataques contra la población civil, sean las modalidades operativas usadas por las partes enfrentadas.

Es por esto, que "los esfuerzos financieros de las nuevas guerras están asociados con el aumento de la predación local, por lo que las batallas son escasas y la guerra es dirigida principalmente contra los civiles. El nuevo tipo de guerra es, en gran medida, una condición social predatoria" (Kaldor, 2001, 15-16).

En Colombia se destaca el trabajo de Rubio (1999), quien sostiene que en este país no existe diferencia entre delincuentes comunes y delincuentes políticos o paramilitares, ya que todos producen los mismos efectos en la sociedad; además, el accionar militar de las organizaciones paramilitares produce innumerables afectaciones sobre la vida y la propiedad, y sus ánimos rentísticos son los que determinan las prácticas que realizan.

En el mismo sentido, Salazar y Castillo (2001) utilizan la teoría de los juegos y la teoría económica del conflicto para sostener que el conflicto armado colombiano es el triste resultado de la acción local de actores armados y no armados, que se adaptaron a la supervivencia con elevados niveles de incertidumbre, poca solidaridad y ausencia de normas que regulen las relaciones entre los individuos. Estos autores, sostienen que las guerrillas y los paramilitares nacieron en contextos de injusticia y violencia, pero esconden fines primordialmente económi- 
cos, de ahí que se beneficien más de la guerra que de la paz.

Sin duda, estas caracterizaciones resultan útiles, aunque no suficientes, pues obligan a no perder de vista la complejidad de las organizaciones paramilitares, y dan elementos para plantear nuevas categorías de análisis y obtener una mayor comprensión de la realidad colombiana. Otro componente al cual los analistas le han dado poca relevancia es la incidencia de las políticas de Estado sobre el paramilitarismo, políticas que han oscilado entre la connivencia y el tratamiento político.

Las teorías anteriores podrían servir para explicar de algún modo la longevidad de los actores armados ilegales colombianos y su permanencia y ascenso post-guerra fría, en el sentido de que el haber generado fuentes permanentes de financiamiento les ha permitido crecer y mantener sus estructuras armadas.

En este sentido, Echandía (2013) demuestra que la expansión paramilitar no se basó en lógicas contrainsurgentes, sino en objetivos económicos principalmente ligados al control del narcotráfico. De hecho, este autor comprueba que su eje de despliegue estratégico se constituye desde las zonas de cultivo y los centros de procesamiento pasando por los corredores que conducen hasta los puntos de embarque. Más específicamente, las Autodefensas buscaron consolidar una especie de línea fronteriza que separara al norte del centro del país, esto con el fin de controlar totalmente los cultivos y laboratorios ubicados entre Urabá (frontera con Pana- má), Bajo Cauca, sur de Bolívar y el Catatumbo (frontera con Venezuela). Rodolfo Escobedo, sintetiza lo antes expuesto:

“A partir de esta franja el Bloque Norte de las AUC manejó, hacia el norte, los corredores a la Costa Atlántica, Venezuela y Panamá, y en particular hacia el Chocó, el Urabá, Sucre, Bolivir, Atlántico, la Sierra Nevada de Santa Marta, asi como la Serranía del Perijá y los límites entre Colombia y Venezuela, desde la Guajira hasta Norte de Santander, pasando por el Cesar" (Escobedo, 2011, 16).

Para entender las dinámicas del paramilitarismo en las ciudades y especialmente en Barranquilla, hay que delimitar sus objetivos al control del monopolio de la coerción y la prestación de seguridad a un conjunto de actividades económicas proclives al control del crimen organizado $^{3}$, tales como las plazas de mercado, la extorsión a los pequeños y medianos comerciantes, el contrabando y el narcotráfico, entre otras. En varios casos, la infiltración de los cargos de elección popular como los Concejos y las Alcaldías, lo que en la práctica le proporciona grandes ganancias por efecto de la contratación pública que cooptan, impunidad judicial y la posibilidad de crear su propia red clientelar (Duncan, 2005). En este sentido, el paramilitarismo en la

3. El crimen organizado es definido en el literal a del artículo 2 de la Carta de las Naciones Unidas contra el crimen transnacional como: "un grupo estructurado de tres o más personas que exista durante cierto tiempo y que actúe concertadamente con el propósito de cometer uno o más delitos graves o delitos tipificados con arreglo a la presente Convención con miras a obtener, directa o indirectamente, un beneficio económico u otro beneficio de orden material". 
ciudad de Barranquilla operó como una mafia, entendida esta como una forma superior de crimen organizado, que se basa en el cobro de un impuesto a cambio de protección a individuos u organizaciones y las actividades económicas que realizan (legales o ilegales indistintamente), es decir, son empresarios de la protección. Todo este esquema de protección se funda en la fuerza o la amenaza de su uso, en pocas palabras "quien no paga la extorsión es violentado automáticamente" (Gambetta, 2000).

En cuanto a su accionar político, vale la pena aclarar que en Barranquilla no lograron someter o cooptar a las elites económicas ni a los barones electorales tradicionales como sí sucedió en Santa Marta, Sincelejo y Valledupar (Pedraza y Olaya, 2011). En este sentido, sus dinámicas políticas en esta ciudad, se encuadraron dentro del concepto de Reconfiguración Cooptada del Estado desarrollado por Garay y Salcedo (2012).

\section{Antecedentes}

Según el Observatorio del Programa Presidencial de Derechos Humanos y DIH (2005), la presencia de crimen organizado en la ciudad de Barranquilla no es reciente. Se remonta a la década de los 70 del siglo pasado, momento en el cual operaron en la ciudad grupos dedicados a la mal llamada limpieza social. Al mismo tiempo, se conformaron organizaciones delincuenciales dedicadas al hurto, asentándose en barrios periféricos como La Chinita, El Ferry y Rebolo. Con el tiempo, los miembros de estas bandas se dedicaron, entre otras cosas, a actividades rela- cionadas con el sicariato llegando a prestar sus servicios al narcotráfico y el paramilitarismo 4 .

El narcotráfico ha sido un elemento central de las dinámicas recientes de la violencia en Barranquilla. Es importante señalar que en los 70 cuando la bonanza marimbera estaba en pleno desarrollo, muchos marimberos guajiros se trasladaron a Barranquilla. Para Sánchez (2003), la instalación del sicariato como práctica reiterada para el cobro de cuentas o la resolución de conflictos es una evidencia de su paso a la ciudad. De esta manera, hacia finales de los 70 e inicios de $\operatorname{los} 80$, se fue incubando toda una tradición socio-cultural en torno al narcotráfico.

Si bien Barranquilla no ha sido el eje sobre el que gravita el narcotráfico colombiano ni la sede de un cartel poderoso, sí ha sido un espacio utilizado tradicionalmente por miembros de mafias de todo el país, por su privilegiada condición de puerto marítimo y desembocadura del río Magdalena. Precisamente, esta ubicación geográfica ha hecho de esta ciudad un punto estratégico para la exportación de droga y el ingreso de ar-

4. Sobre la historia, expansión y estrategias del paramilitarismo en Colombia, véase: Rangel, A. (editor) (2008). El poder paramilitar. Bogotá: Fundación Seguridad \& Democracia, Editorial Planeta; Echandía, C. (2013). Narcotráfico: Génesis de los paramilitares y herencia de bandas criminales. Bogotá: Fundación Ideas para la Paz; Revista Arcanos, No. 13, 2007. Paramilitares y políticos. Bogotá: Corporación Nuevo Arco Iris; Corporación Observatorio para la Paz (2002). Las verdaderas intenciones de los paramilitares. Bogotá: Intermedio Editores; Romero, M. (editor) (2007). Parapolítica. La ruta de la expansión paramilitar y los acuerdos políticos. Bogotá: Corporación Nuevo Arco Iris, Intermedio Editores; López, C. (editora) (2010). Y refundaron la patria ... De cómo mafiosos y políticos reconfiguraron el Estado colombiano. Bogotá: Corporación Nuevo Arco Iris; Congreso Visible, Dejusticia, Grupo Método, MOE, Editorial Debate; Romero, M. (editor) (2011). La economía de los paramilitares. Redes de corrupción, negocios y política. Bogotá: Editorial Debate. 
mas e insumos químicos. Esto, con un contexto social de alta tolerancia frente al contrabando y el lavado de activos provenientes del tráfico de drogas.

A mediados de los 80, se conforma el Cartel de la Costa, con centro de operaciones en Barranquilla y Santa Marta. En la segunda mitad de los 90 este cartel fue debilitado entre otros factores por el accionar de las autoridades y por la llegada a la región de nuevos agentes ilegales, destacándose los representantes de los narcotraficantes del norte del Valle, quienes coparon los espacios dejados por el Cartel de la Costa, junto a ellos se hacen fuertes los contrabandistas y narcotraficantes de La Guajira (Observatorio del Programa Presidencial de Derechos Humanos y DIH, 2012).

Hacia fines de los 90, el control del crimen en la ciudad, lo ejercía la banda de Dino Meza, que según el Diario El Tiempo "era la dueña de las calles de Barranquilla, recogía por seguridad y extorsiones más de 10 millones de pesos diarios" (El Tiempo.com, 2007). En 1999 llegaron a Barranquilla los primeros hombres de las Autodefensas Unidas de Colombia (AUC) enviados por 'Jorge 40', para ese momento, Dino Meza ya controlaba todas las actividades susceptibles de extorsión. Por esto 'Yair', el primer jefe paramilitar que operó en la ciudad, citó a Meza para que se uniera a las AUC y en dicha reunión este último fue asesinado. Desde ese momento en Barranquilla y el Atlántico hicieron presencia activa dos estructuras del Bloque Norte de las AUC, más precisamente el "Grupo Atlántico" entre los años 2000 y 2003 y el Frente José Pablo Díaz (en adelante FJPD) entre los años 2003 y $2006^{5}$.

La importancia de Barranquilla en el despliegue de las AUC en el Norte de Colombia quedó en evidencia en la versión libre ante la fiscal de Justicia y Paz, del segundo hombre de las AUC en el norte de Colombia, Rodrigo Tovar Pupo ('Jorge 40'), en la cual afirmó que el objetivo central de todas las acciones político-militares del Bloque Norte de las AUC era la captura de Barranquilla, según Tovar Pupo "meterse en el departamento del Atlántico, era una obsesión de la casa Castaño" (Pedraza y Olaya, 2011, 191). Es necesario aclarar que en Barranquilla, la presencia de los paramilitares no obedeció a un objetivo contrainsurgente, ya que las organizaciones guerrilleras nunca han tenido una presencia activa en la capital del departamento ${ }^{6}$, sino que por el contrario, su expansión está ligada a las raíces históricas que los unen con el narcotráfico y al crimen organizado.

5. El Frente cambia de nombre en el año 2003, en honor a José Pablo Díaz, quien fue líder de la estructura paramilitar del departamento del Atlántico entre el 2000 y 2003, año en que es asesinado en una emboscada del Frente XIX de las FARC en la troncal del Caribe, en el trayecto entre Ciénaga y Fundación.

6. Sobre la presencia de las organizaciones guerrilleras en la ciudad de Barranquilla y el departamento del Atlántico véase: Observatorio del Programa Presidencial de Derechos Humanos y DIH (2005). Dinámica reciente de la violencia en Barranquilla. Bogotá: Vicepresidencia de la República de Colombia; Observatorio del Programa Presidencial de Derechos Humanos y DIH (2012). Diagnóstico de la situación de Derechos Humanos y Derecho Internacional Humanitario del departamento del Atlántico 2000 - I semestre de 2011. Bogotá: Vicepresidencia de la República de Colombia; López, C. (coordinadora y editora) (2008). Monografia político-electoral del departamento del Atlántico 1997 a 2007. Bogotá: Misión de Observación Electoral, Corporación Nuevo Arco Iris, Universidad de los Andes. 


\section{Expansión y consolidación}

El proceso de expansión y consolidación del FJPD de las AUC, se presenta entre los años 2003 y 2006 (año de su desmovilización). En este lapso de tiempo, la estructura paramilitar del departamento del Atlántico estuvo bajo el mando de Edgar Ignacio Fierro, alias 'Don Antonio'?

Fierro, siguió la misma estrategia de control social y expansión territorial usada por las Autodefensas Campesinas de Córdoba y Urabá (ACCU), esta estrategia consistía en ganar el apoyo de la Fuerza Pública y las instituciones del Estado, establecer alianzas con políticos locales, instalar candidatos propios en corporaciones públicas y hacer ciertas inversiones económicas con el fin de construir bases sociales (Arcanos, 2007); el orden social que buscaba instalar el paramilitarismo en la ciudad de Barranquilla, se dirigía hacia tres áreas específicas:

La económica-social: busca ordenar y controlar las actividades económicas legales e ilegales, jerarquizando unas sobre otras y regulando

7. "Antes de ingresar al paramilitarismo, Fierro habia pasado por las zonas más conflictivas del país como oficial del Ejército. Como teniente, primero estuvo en Barrancabermeja, cuando el Bloque Central Bolivar libraba una guerra con las milicias urbanas del ELN. También pasó por el sur de Bolívar y patrulló en las comunas de Medellín. Y como capitán estuvo en el Cesar. Fierro llegó a las AUC en marzo de 2003 después de haber sido destituido por haber hecho un allanamiento ilegal. Como se lo contó a Verdad abierta, su llegada a las AUC se dio después de haber salido por la puerta de atrás de las Fuerzas Armadas cuando, de civil, organizó un operativo para supuestamente incautar un armamento a un grupo guerrillero en el Cesar. Cuando llegó al sitio no habia ni armas ni guerrilleros y después de una investigación el general Carlos Alberto Ospina, entonces comandante de las Fuerzas Militares, decidió expulsarlo del Ejército" (verdadabierta.com, 2011a). las relaciones sociales que nacen de este ordenamiento.

La política institucional: se centra en la eliminación de las fuerzas políticas opositoras, en la creación de nuevos actores y referentes sociales, políticos y organizativos, y en la implementación de mecanismos de control y coerción que regulen la convivencia social.

La burocrática-administrativa: reglamenta las funciones y alcances de las instituciones públicas con respecto a sus intereses particulares y la gestión de los mismos.

El accionar violento del paramilitarismo en la capital del Atlántico se dirigió en contra de todas las personas, grupos u organizaciones que se opusieran o entorpecieran la construcción de este orden social. En la práctica, esto se tradujo en una significativa reconfiguración del escenario social, delincuencial y en menor medida el espectro político de esta ciudad.

El impacto social causado por la expansión y consolidación del FJPD en la ciudad de Barranquilla, produjo un dramático aumento de la criminalidad y la violación de los Derechos Humanos en la capital del Atlántico, según verdadabierta.com (2011), esta estructura paramilitar entre los años 2004 y 2006 cometió 1.664 homicidios. Con la llegada del FJPD, el desplazamiento forzado en Barranquilla pasó de 966 personas en 1999 a 6.297 en el 2000 y a 10.778 personas en el 2001.

Hay que resaltar que en estas cifras no se tienen en cuenta muchos homicidios cometidos por el FJPD y que fueron registrados como muertes comunes o no ligadas a la acción paramilitar, 
esta afirmación se desprende de declaraciones realizadas por 'Don Antonio', en una diligencia judicial:

"Don Antonio le contó a la fiscal que mensualmente se reunía en Cartagena o Santa Marta con los comandantes militares de las AUC de diferentes zonas. En esos encuentros, narró, "cada comandante entregaba una relación de las bajas de sus respectivas zonas". Don Antonio dijo que la única regla que tenían que cumplir los paramilitares bajo su mando era la de no asesinar a más de tres personas a la vez, para evitar presión de los medios y las autoridades" (Semana.com, 2007).

\section{Medios y fines}

La violencia paramilitar ejercida con el fin de lograr el control social, político y económico de la ciudad de Barranquilla, se edificó sobre tres políticas específicas que la Sala de Justicia y Paz del Tribunal Superior del Distrito Judicial de Bogotá (2011), denominó:

1. Discurso contrainsurgente. Para legitimar su accionar violento contra la sociedad civil de Barranquilla, los paramilitares instalaron un discurso anti-subversivo que sirvió como falso imaginario ideológico para perseguir a aquellas personas o grupos que en el desarrollo de sus actividades se dedicaban a la reivindicación de derechos sociales, económicos y culturales. Esta política, de homicidios selectivos o de violencia discriminada, era fruto de falsos, arbitrarios y descriteriados señalamientos realizados por miembros de la estructura paramilitar dedicados a labores de inteligencia.

Cabe destacar que el FJPD, en el marco de su actividad "contrainsurgente" desplegó una táctica ofensiva que consistió en amenazar, desplazar y asesinar a defensores de derechos humanos, académicos, estudiantes, políticos de izquierda, sindicalistas, líderes comunitarios, miembros de las comunidades LGBT (lesbianas, gays, bisexuales y transexuales). Según verdadabierta.com (2012) solo durante el año 2003, la persecución paramilitar contra los miembros de los sindicatos llegó a tal punto que amenazaron a 63 sindicalistas afiliados a la Central Unitaria de Trabajadores (CUT), Anthoc, Sintrahoincol, Sintraimargra, Sintranaviera, Sutimac, Sintrabancol, Sinthol, Sintrainal Barranquilla, Sindicato de Galapa, Sintracarne, Sintraelecol Atlco., Sintraelecol Corelca, Sintracoolechera, Sintraagrícola, Sintrago y Fecode.

2. Limpieza social. Este eufemismo se utilizó para justificar una serie de asesinatos que tenían como objetivo generar una percepción de seguridad en los sectores de la ciudad que eran extorsionados por el FJPD. Bajo esta política:

"el derrotero ideológico deja de inscribirse en el estadio de lo político para radicarse en lo ético moral manipulando estándares de normalidad y anormalidad dentro del conglomerado social. A diferencia de la política de homicidios selectivos, donde el enemigo se ubica en cabeza de aquellos señalados como auxiliares de la subversión, en la política de limpieza social el enemigo en sentido 
abstracto deja de ser político y se tiene por este a aquel que, supuestamente, ha cometido delitos comunes, consume estupefacientes o simplemente genera sospecha a la organización" (Sala de Justicia y Paz del Tribunal Superior del Distrito Judicial de Bogotá, 2011, 151).

Por otro lado, la eliminación de la delincuencia común posibilita la regulación de la criminalidad en todos los niveles y la construcción del monopolio sobre ciertos delitos que producen un alto valor operativo, tales como: el sicariato, el secuestro, la extorsión, el robo de valores y el transporte y acopio de drogas y el lavado de activos. En este sentido, Duncan (2013) afirma que toda protección del narcotráfico implica una amenaza, ya que solo es posible ofertar protección cuando se está en real capacidad de amenazar. Una organización ilegal como la paramilitar, solo puede ofrecer una protección creíble cuando demuestra que tiene la suficiente fuerza para someter a otras organizaciones armadas.

3. Homicidios retributivos. En este caso, la muerte se asume como la consecuencia natural por el no pago de los tributos que el grupo paramilitar exige para sostener su actividad ilegal. En este punto cabe señalar que el eje central sobre el cual giró la dinámica paramilitar en esta ciudad fue la consecución de recursos económicos para el Bloque Norte.

Es por eso que según Pedraza y Olaya (2011), 'Don Antonio' junto a Gregorio Mangones ('Carlos Tijeras'), conformaron “La Empresa”, una estructura económica de tipo mafioso, que tenía como fin la creación de un presupuesto estable que permitiera una operatividad continua del proyecto paramilitar por medio de la monopolización de mercados legales e ilegales a escala regional.

En el caso de Barranquilla, la extorsión a comerciantes se convirtió en una práctica común, según verdadabierta.com (2011), Oswaldo Calvano era el encargado del cobro del "impuesto" en el mercado público de la ciudad, del cual obtenían un aproximado de 50 millones de pesos mensuales. Otro gremio afectado directamente por la actividad extorsiva del paramilitarismo en la ciudad de Barranquilla fue el de los tenderos, quienes durante el año 2005 pagaron 3.000 millones de pesos en extorsiones ${ }^{8}$ (El Tiempo.com, 2005).

Pero la mayor fuente de ingresos de esta estructura paramilitar la constituyó el monopolio que ejercieron sobre la protección, transporte, acopio y control de puntos de exportación de cocaína. El encargado de las actividades relacionadas con el narcotráfico fue Miguel Villarreal Archila ('Salomón'), un subintendente retirado de la Policía.

En su versión libre, alias 'Salomón' confesó que en asocio con miembros de la Policía, los narcotraficantes entre los años 2003 y 2006 exportaron por los puertos del Atlántico más de

8. En un aparte de la Sentencia proferida por la Sala de Justicia y Paz del Tribunal Superior del Distrito Judicial de Bogotá (2011) en contra de Edgar Fierro ('Don Antonio'), se lee lo siguiente: "Otro aspecto importante de resaltar es la muerte selectiva de algunos tenderos en la ciudad de Barranquilla y el municipio de Soledad. En el año 2004 fueron asesinados 20 tenderos, 9 en el 2005" (p. 24). 
100 toneladas de cocaína, también afirmó que los paramilitares les cobraron por cada kilo un impuesto de entre 50 y 75 dólares. Según ‘Salomón', por este concepto el FJPD recaudó más de dos millones de dólares anuales (verdad abierta, 2011b).

La Revista Semana (2003), registró un hecho que dejó en evidencia la anterior información. En agosto de 2003, miembros de la Policía Nacional del departamento del Atlántico, decomisaron 2 toneladas y media de cocaína que luego fueron devueltas a narcos del norte del Valle, previo pago de un soborno gestionado por el Bloque Norte de las AUC que era el encargado de la protección y transporte de la droga. Fue tal la colaboración de la Policía Nacional en este departamento con el Bloque Norte de las AUC, que el Diario El Tiempo en su edición digital del 4 de febrero de 2007, señaló que:

"En Barranquilla empezó a decirse que la coca de los 'paras'se movía libremente por la ciudad. De hecho, el retiro de cinco oficiales de alto rango de la Policía Atlántico en los últimos tres años y la detención de 20 miembros de la institución están relacionados con escándalos como la devolución de tres toneladas de cocaína que habian sido descubiertas en un retén" (E1 Tiempo.com, 2007).

La actividad criminal desplegada por el paramilitarismo en la ciudad de Barranquilla, fue favorecida por la complicidad de agentes estatales que por simpatía, coerción o cooptación facilitaron su expansión y consolidación. En esta ciu- dad se produjo una Reconfiguración Cooptada del Estado, que según Garay y Salcedo (2012), ocurre en contextos de corrupción avanzada, presentando las siguientes características: 1. Participan individuos y grupos sociales legales e ilegales. 2. Los beneficios que persiguen no son solo económicos sino también de tipo penal y de legitimación social. 3. Por medio de la fuerza o la amenaza real de su uso establecen alianzas políticas que complementan o reemplazan la extorsión. 4. Afecta de distintas maneras todos los niveles de la administración pública. Con estas características, la Reconfiguración Cooptada del Estado puede definirse como: "La acción de agentes sociales legales e ilegales, que mediante prácticas ilegales o legales pero ilegitimas, buscan sistemáticamente modificar desde dentro el régimen e influir en la formulación, modificación, interpretación y aplicación de las reglas de juego social y de las politicas públicas" (Garay y Salcedo, 2012, 36). Estas acciones son desarrolladas con el fin de materializar sus objetivos en el largo plazo y lograr la legitimación política y social de sus intereses, aunque dichos intereses no busquen el bien común.

Las interacciones desarrolladas por la comandancia del FJPD de las AUC y distintos agentes estatales escenifican un proceso de Reconfiguración Cooptada del Estado en la ciudad de Barranquilla. Con respecto a esto, 'Don Antonio' ha reconocido en varias declaraciones públicas que tuvo estrechos vínculos con Gabriel Turizo, quien fuera director del Cuerpo Técnico de Investigaciones (CTI) de la Fiscalía General 
de la Nación en los departamentos de Atlántico y La Guajira. 'Don Antonio' le pagó a Turizo 20 millones de pesos cuando este funcionario le informó que habían varios operativos en su contra y era inminente su captura. Esta información, posibilitó el escape del comandante paramilitar. En la misma línea, 'Don Antonio' confesó que, con la ayuda de funcionarios de la Registraduría Nacional, sustrajo las fichas con sus huellas dactilares y toda la información que había sobre él en esa entidad. Así mismo, contó también que recibió ayuda del excongresista Pedro Peñalosa, suplente del también excongresista Jorge Luis Caballero, condenado por la Corte Suprema de Justicia a seis años de prisión por sus vínculos con el paramilitarismo. 'Don Antonio' ha sostenido que el entonces congresista Peñalosa, le había prestado su vehículo blindado oficial y que, además, le entregó carné para que sus hombres se hicieran pasar por guardaespaldas del parlamentario (Semana.com, 2007).

Estos hechos, ponen de relieve la debilidad de las instituciones estatales en el plano local, lo que permite la instrumentalización por parte de agentes ilegales, precisamente de aquellas instituciones cuya función primordial es el combate al crimen organizado (Arévalo y Ortega, 2013). Los hechos antes referenciados muestran cómo el FJPD logró que varias instituciones públicas de la ciudad de Barranquilla y del departamento del Atlántico estuvieran a su servicio.

\section{El esquivo poder político}

Es importante destacar que si bien el parami- litarismo logró permear instituciones públicas en la ciudad de Barranquilla y cooptar por distintos medios a varios agentes estatales, en esta ciudad no lograron penetrar las estructuras políticas, ya que los barones electorales de la ciudad ${ }^{9}$, se resistieron a las alianzas con el paramilitarismo y no compartieron la administración pública con actores ilegales a diferencia de ciudades como Montería, Santa Marta, Sincelejo y Valledupar en las que el Bloque Norte de las AUC se apoderó del poder político-administrativo ${ }^{10}$.

Esta especie de pacto de "no agresión" tácito, entre las elites políticas tradicionales de la ciudad de Barranquilla y el FJPD podría explicarse desde el planteamiento de Peter Waldman (1997), quien sostiene que muchas veces las elites no realizan los esfuerzos necesarios para terminar con la actividad criminal, ya que al superar el shock producido por la disputa y pérdida del control político y militar sobre una parte del territorio, se adaptan rápidamente a esta nueva situación y comparten la soberanía, especialmente cuando el porcentaje de recursos económicos y densidad demográfica presentes

9. Sobre estos véase: López, C. (coordinadora y editora) (2008). Monografia político-electoral del departamento del Atlántico 1997 a 2007. Bogotá: Misión de Observación Electoral, Corporación Nuevo Arco Iris, Universidad de los Andes.

10. Sobre la captura del Estado llevada a cabo por el Bloque Norte de las AUC en los departamentos de Cesar, Córdoba y Magdalena véase en su orden: Cubides, F. (2008). "Narcotráfico y paramilitarismo: ¿matrimonio indisoluble?”. En Rangel, A. (editor), El poder paramilitar. Bogotá: Fundación Seguridad \& Democracia, Editorial Planeta; López, C. (2008) (coordinadora y editora). Monografía político-electoral del departamento de Córdoba 1997 a 2007. Bogotá: Misión de Observación Electoral, Corporación Nuevo Arco Iris, Universidad de los Andes; Zúñiga, P. (2007). "Ilegalidad, control local y paramilitares en el Magdalena". En Romero, M. (editor), $\mathrm{Pa}$ rapolítica: la ruta de la expansión paramilitar. Bogotá, Colombia: Corporación Nuevo Arco Iris, Intermedio Editores. 
en el territorio "perdido" no afecta o amenaza su posición dominante y mantiene hacia el exterior una percepción de aparente legitimidad. Este tipo de situaciones es definida por Mauricio Romero (2007) como un "desorden duradero", es decir, "circunstancias en las cuales los gobiernos (en este caso locales) no son capaces de abordar la raíz de los problemas, pero tampoco dejan colapsar el sistema".

Pero el hecho de no haber logrado el control político de la ciudad no quiere decir que no lo intentaron. Curiosamente, la única fuerza política que tranzó con el FJPD fue el Movimiento Ciudadano, un movimiento de centro-izquierda, conformado por la convergencia de movimientos políticos como la Alianza Democrática M-19 y otros movimientos sociales de izquierda, que se agrupan en torno a la candidatura a la Alcaldía de Barranquilla de Bernardo Hoyos, quien también recibió el apoyo de sectores liberales como el movimiento Voluntad Popular del senador Fuad Char.

La candidatura de Hoyos se construye sobre un proyecto político de tipo popular y progresista, convirtiéndose en el mayor opositor de los tradicionales barones electorales de la ciudad (José Name y Roberto Gerlein), con un discurso populista que denunciaba la corrupción y los abusos presentes en la ciudad causados por los antes citados. Esta nueva fuerza política popular y de izquierda que se enfrenta a los caciques tradicionales, sale victoriosa y logra obtener en las elecciones de 1992 la Alcaldía de Barranquilla, con Bernardo Hoyos, y la Gobernación de
Atlántico, con Gustavo Bell. Una vez terminado su periodo de gobierno, Hoyos logra "traspasar" electoralmente la alcaldía a un candidato de su mismo movimiento, Edgar George (1995-1997), y luego repite Hoyos en el periodo 1998-2000. El caudal electoral del Movimiento Ciudadano se ve afectado con el triunfo de Humberto Caiaffa (2001-2003), pero logra recuperarse con la victoria de Guillermo Hoenigsberg (2004-2007), este sería el último Alcalde por ese movimiento en Barranquilla. Para este momento, salvo la primera elección de Hoyos, todos las victorias electorales del Movimiento Ciudadano contaron con el respaldo de José Name y en la elección de Guillermo Hoenigsberg fueron apoyados por los Gerlein (Caicedo, 2008).

Precisamente fue durante la campaña electoral de Hoenigsberg que el FJPD logra su ingreso a los espacios políticos de la ciudad. Carlos Mario García ('Gonzalo'), coordinador político del FJPD, ha contado públicamente que le entregó a la campaña de Hoenigsberg 2.500 millones de pesos a cambio de su participación activa en la administración. Según el propio 'Gonzalo', el FJPD llegó a proyectar que el $40 \%$ de la Alcaldía de Barranquilla sería suyo.

En esta ciudad, los intereses paramilitares se concentraron más en la captura y apropiación de las finanzas públicas que en la representación política. En este sentido, el medio usado para dicha captura fueron las concesiones, destacándose las siguientes: Concesión a Inversiones Los Ángeles para la gestión y recaudo tributario. La concesión la entrega inicialmente Bernardo 
Hoyos y posteriormente en la administración de Hoenigsberg Inversiones Los Ángeles cede la concesión a Métodos y Sistemas, tomada en parte por intereses privados y capitales ilegales.

La monografía político-electoral del departamento del Atlántico 1997-2007, realizada por la Misión de Observación Electoral y la Corporación Nuevo Arco Iris, sintetiza de la siguiente manera la forma como el Bloque Norte de las AUC y su FJPD intervinieron económica y políticamente la administración pública de Barranquilla:

“-Concesión del recaudo de impuestos a privados: el alcalde de Barranquilla, Hoyos, da en concesión el recaudo de sus impuestos, a Inversiones Los Ángeles Ltda., por medio del Contrato de Consultoría GPCM-CONS-001-2000, cuyos accionistas principales eran el exsenador David Name y su entonces esposa, Albertina Guerra de la Espriella. -Cesión del contrato: Inversiones Los Ángeles Ltda. cede el contrato de recaudo de impuestos a la empresa Métodos \& Sistemas S.A. A finales de diciembre de 2003. -Cambio de socios del concesionario Métodos y Sistemas permitió que entraran socios y funcionarios presuntamente relacionados con 'Jorge 40'. -Asesinato de socios del concesionario. Eduardo Losada (presidente de Métodos y Sistemas y quien presuntamente había sido quien entregó los dineros para la campaña de Hoenigsberg fue asesinado en junio de 2004. -Según confesión de alias 'Don Antonio' los paramilitares obtenían del concesionario Métodos y Sistemas un aporte mensual de veinte millones de pesos para las Autodefensas Unidas de Colombia (AUC)" (MOE - CNAI, 2008, 47-48-49).

Con la financiación ilícita de la campaña de Guillermo Hoenigsberg, logran posteriormente afianzar sus alianzas políticas y electoral regionales, por medio de la coerción armada y el fraude electoral los senadores Mauricio Pimiento, Álvaro Araújo y Dieb Maloof ${ }^{11}$, obtuvieron el apoyo electoral de la administración de Hoenigsberg en Barranquilla y de la alcaldesa de Soledad Astrid Barraza (MOE - CNAI, 2008).

Precisamente la Corte Suprema de Justicia, acaba de compulsar copias a la Fiscalía General de la Nación para que investigue al exalcalde Hoenigsberg, basándose en una declaración rendida los días 1 y 2 de agosto de 2013, por el excomandante paramilitar Diego Fernando Murillo Bejarano, alias 'Don Berna', ante una comisión de fiscales delegados, en dicha declaración, 'Don Berna' afirmó que:

"él era Alcalde de Barranquilla, él estuvo en Santa Fe de Ralito, a él lo lleva un señor al que le hicieron un atentado del que salió inválido, que le decíamos Yuyo (...) el objetivo era conocerlo y saber que él era una persona cercana a las Autodefensas, que tuvo el apoyo y respaldo del Bloque Norte, concretamente del señor (Rodrigo Tovar Pupo) 'Jorge 40', también para intercambiar algunos concep-

11. Los tres fueron condenados a penas privativas de la libertad por sus nexos con los grupos paramilitares. 
tos e ideas, ya que una de las labores mías en la organización pues era la parte política, y yo sé que él era cercano a la organización y tuvo el respaldo y el apoyo de 'Jorge 40', (elheraldo.com.co, 2013).

\section{CONCLUSIONES}

Del anterior análisis pueden extraerse las siguientes conclusiones:

1. La presencia del paramilitarismo en la ciudad de Barranquilla, no obedeció a una estrategia contrainsurgente sino a sus estrechos vínculos con el narcotráfico y el crimen organizado.

2. Los objetivos del paramilitarismo en la ciudad de Barranquilla, se centraron en el control del monopolio de la coerción y la prestación de seguridad a un conjunto de actividades económicas proclives al control del crimen organizado tales como las plazas de mercado, la extorsión a los pequeños y medianos comerciantes, el contrabando y el narcotráfico, entre otras.

3. La actividad criminal desplegada por el paramilitarismo en la ciudad de Barranquilla, fue favorecida por la complicidad de agentes estatales que por simpatía, coerción o cooptación facilitaron su expansión y consolidación, produciéndose en este caso una parcial reconfiguración cooptada del Estado.

4. A pesar de que el FJPD de las AUC, logró permear instituciones públicas en la ciudad de Barranquilla y cooptar por distintos medios a varios agentes estatales, en esta ciudad no lograron penetrar completamente las estructuras políticas, ya que los barones electorales de la ciudad, se resistieron a las alianzas con el paramilitarismo y no compartieron la administración pública con actores ilegales a diferencia de ciudades como Montería, Santa Marta, Sincelejo y Valledupar en las que el Bloque Norte de las AUC se apoderó totalmente del poder político-administrativo.

\section{REFERENCIAS}

Arévalo, J. y Ortega, J. (2013). "Comercio delictivo, lavado de activos y captura del Estado". En Giraldo, J. (editor), Economía criminal y poder politico. Medellín: Universidad EAFIT, Colciencias.

Botero, R. (1996). En busca de los desaparecidos. Análisis político-criminal de la conducta y su normatividad. Serie Textos de Divulgación, $\mathrm{N}^{\circ} 19$.

Camacho, A. (2002). Credo, necesidad y codicia: los alimentos de la guerra. En Revista Análisis Político, 46, 137-150.

Caicedo, E. (2008). "Estructuras de poder político y electoral". En López, C. (coordinadora y editora), Monografía político-electoral del departamento del Atlántico 1997 a 2007. Bogotá: Misión de Observación Electoral, Corporación Nuevo Arco Iris, Universidad de los Andes.

Collier, P. (2001). Causas económicas de las guerras civiles y sus implicaciones para el diseño de políticas. En Revista El Malpensante, 30, 13-35. 
Collier, P. (2004). El desafio global de los conflictos locales. Bogotá, Colombia: Banco Mundial.

Corporación Observatorio para la Paz (2002). Las verdaderas intenciones de los paramilitares. Bogotá: Intermedio Editores.

Cubides, F. (2008). "Narcotráfico y paramilitarismo: ¿matrimonio indisoluble?”. En Rangel, A. (editor), El poder paramilitar. Bogotá: Fundación Seguridad \& Democracia, Editorial Planeta.

Duncan, G. (2005). Del campo a la ciudad en Colombia. La infiltración urbana de los señores de la guerra. Bogotá, Colombia: Documento Cede. [En línea]: http://economia.uniandes.edu.co/investigaciones_y_ publicaciones/CEDE/Publicaciones/ documentos_cede/2005/del_campo_a_la_ ciudad_en_colombia_la_infiltracion_urbana_de_los_senores_de_la_guerra [Consulta: 18-07-2013].

Duncan, G. (2013). "La división del trabajo en el narcotráfico: mercancía, capital y geografía del Estado". En Giraldo, J. (editor), Economía criminal y poder político. Medellín: Universidad EAFIT, Colciencias.

Echandía, C. (2013). Narcotráfico: Génesis de los paramilitares y herencia de bandas criminales. Bogotá: Fundación Ideas para la Paz.

El Espectador.com (2011). Las confesiones de alias 'Gonzalo': "Yo llevé a Hoenigsberg a Ralito", en línea: http://www.elespectador. com/impreso/judicial/articulo-313490-yolleve-hoenigsberg-ralito Consulta 16 de abril de 2013.
El Heraldo.com.co (2011). Revelan detalles de cómo las AUC penetraron la política barranquillera, en línea: http://www.elheraldo.co/ pol-tica/revelan-detalles-de-c-mo-las-aucpenetraron-pol-tica-barranquillera-47551 Consulta 14 de julio de 2013.

El Heraldo.com.co (2013). Corte pide a Fiscalía indagar a Hoenigsberg por parapolítica, en línea: http://www.elheraldo.co/nacional/ corte-pide-fiscalia-indagar-hoenigsbergpor-parapolitica-132317 Consulta 15 de noviembre de 2013.

El Tiempo.com (2005). Por vacunas ocho tenderos muertos, en línea: http://www.eltiempo. com/archivo/documento/MAM-1680005 Consulta 25 de diciembre de 2012.

El Tiempo.com (2007). El silencio, sombra protectora de los paras en Barranquilla, en línea: http://www.eltiempo.com/archivo/ documento/MAM-2377829 Consulta 16 de diciembre de 2012 .

Escobedo, R. (2011). Relaciones del narcotráfico con organizaciones irregulares $y$ delincuenciales y su impacto en la violencia. Bogotá: Vicepresidencia de la República, Observatorio de Derechos Humanos.

Gambetta, D. (2000). "Mafia: the price of distrust". En Gambetta, D. (editor), Trust: making a breaking cooperative relations. Oxford: University of Oxford.

Garay, L. y Salcedo, E. (2012). Narcotráfico, corrupción y Estados. Cómo las redes ilícitas han reconfigurado las instituciones en Colombia, Guatemala y México. Colombia: Editorial Debate. 
Kaldor, M. (2001). Las nuevas guerras. La violencia organizada en la era global. Barcelona, España: Tusquets Editores.

Kalyvas, S. y Arjona, A. (2008). "Paramilitarismo: una perspectiva teórica". En Rangel, A. (editor). El poder paramilitar. Bogotá: Fundación Seguridad \& Democracia, Editorial Planeta.

López, C. (coordinadora y editora) (2008). Monografia político-electoral del departamento del Atlántico 1997 a 2007. Bogotá: Misión de Observación Electoral, Corporación Nuevo Arco Iris, Universidad de los Andes. López, C. (coordinadora y editora) (2008). Monografia político-electoral del departamento de Córdoba 1997 a 2007. Bogotá: Misión de Observación Electoral, Corporación Nuevo Arco Iris, Universidad de los Andes. López, C. (editora) (2010). Y refundaron la patria... De cómo mafiosos y políticos reconfiguraron el Estado colombiano. Bogotá: Corporación Nuevo Arco Iris, Congreso Visible, Dejusticia, Grupo Método, MOE, Editorial Debate.

Negri, A. y Hart, M. (2004). Multitud. Guerra y democracia en la era del Imperio. Argentina: Debate.

Observatorio del Programa Presidencial de Derechos Humanos y DIH (2005). Dinámica reciente de la violencia en Barranquilla. Bogotá: Vicepresidencia de la República de Colombia.

Observatorio del Programa Presidencial de Derechos Humanos y DIH (2012). Diagnóstico de la situación de Derechos Humanos y Derecho Internacional Humanitario del departamento del Atlántico 2000 - I semestre de 2011. Bogotá: Vicepresidencia de la República de Colombia.

Organización de las Naciones Unidas (2004). Convención de las Naciones Unidas contra la Delincuencia Organizada Transnacional. Nueva York: Oficina de las Naciones Unidas contra la Droga y el Delito.

Pedraza, H. y Olaya, Á. (2011). "Regalías, cooperativas y finanzas paramilitares en la costa Caribe". En Romero, M. (editor), $L a$ economía de los paramilitares. Redes de corrupción, negocios y politica. Bogotá: Editorial Debate.

Rangel, A. (editor) (2008). El poder paramilitar. Bogotá: Fundación Seguridad \& Democracia, Editorial Planeta.

Revista Arcanos No. 13 (2007). Paramilitares y políticos. Bogotá: Corporación Nuevo Arco Iris.

Romero, M. (editor) (2007). Parapolítica. La ruta de la expansión paramilitar y los acuerdos políticos. Bogotá: Corporación Nuevo Arco Iris, Intermedio Editores.

Romero, M. (2007). "Nuevas guerras, paramilitares e ilegalidad: una trampa difícil de superar". En Romero, M. (editor), Parapolítica: la ruta de la expansión paramilitar. Bogotá, Colombia: Corporación Nuevo Arco Iris, Intermedio Editores.

Romero, M. (editor) (2011). La economía de los paramilitares. Redes de corrupción, negocios y política. Bogotá: Editorial Debate. 
Rubio, M. (1999). Crimen e impunidad. Precisiones sobre la violencia. Bogotá, Colombia: Tercer Mundo Editores-Cede.

Sánchez Bonnet, L. (2003). "Barranquilla: Un espacio para la sospecha”. En Sánchez Bonnet, L. (Compilador). Barranquilla: Lecturas Urbanas. Bogotá.

Sala de Justicia y Paz del Tribunal Superior del Distrito Judicial de Bogotá (2011). Magistrada Ponente: Léster María González Romero. Radicación: 110016000253200681366. Postulado: Edgar Ignacio Fierro Flores.

Salazar, B. y Castillo, M. (2001). La hora de los dinosaurios. Conflicto y depredación en Colombia. Bogotá, Colombia: Universidad del Valle, Cerec-Cidse.

Semana.com (2003). El general en su laberinto, en línea: http://www.semana.com/nacion/ articulo/el-general-su-laberinto/58805-3 Consulta: julio 30 de 2013.

Semana.com (2007). Los crímenes de 'Don Antonio', en línea: http://www.semana.com/ nacion/articulo/los-crimenes-don-antonio/84647-3 Consulta: 16 de abril de 2013.
Verdad abierta.com (2009). 'Don Antonio', el hombre detrás del computador, en línea: http://verdadabierta.com/la-historia/1513don-antonio-el-hombre-computador Consulta: 12 de enero de 2013.

Verdad abierta.com (2011a). La primera sentencia de 'Don Antonio' en Justicia y Paz, en línea: http://www.verdadabierta.com/ bandera/3741-condena-don-antonio Consulta: 16 de diciembre de 2012 .

Verdad abierta.com (2011b). El paso macabro de las AUC por el Atlántico, en línea: http://www.verdadabierta.com/component/ content/article/83-juicios/3601-el-pasomacabro-del-bloque-norte-por-el-atlantico Consulta: 30 de julio de 2013.

Waldman, P. (1997). Cotidianización de la violencia: el ejemplo de Colombia. Análisis Político, 32, 33-51.

Zúñiga, P. (2007). "Ilegalidad, control local y paramilitares en el Magdalena". En Romero, M. (editor), Parapolítica: la ruta de la expansión paramilitar. Bogotá, Colombia: Corporación Nuevo Arco Iris, Intermedio Editores. 